Article

\title{
Thermocouple and Infrared Sensor-Based Measurement of Temperature Distribution in Metal Cutting
}

\author{
Abdil Kus ${ }^{1, *}$, Yahya Isik ${ }^{1, \dagger}$, M. Cemal Cakir ${ }^{2, \dagger}$, Salih Coşkun ${ }^{1, \dagger}$ and Kadir Özdemir ${ }^{2, \dagger}$ \\ 1 Vocational School of Technical Science, Uludag University, 16059 Bursa, Turkey; \\ E-Mails: yyisik@gmail.com (Y.I.); coskuns@uludag.edu.tr (S.C.) \\ 2 Department of Mechanical Engineering, Uludag University, 16059 Bursa, Turkey; \\ E-Mails: mcemalcakir@gmail.com (M.C.C.); kadirzdemir@gmail.com (K.Ö.) \\ $\dagger$ These authors contributed equally to this work. \\ * Author to whom correspondence should be addressed; E-Mail: abdilkus@gmail.com; \\ Tel.: +90-224-294-2344; Fax: +90-224-294-2301.
}

Academic Editor: Markus Sigrist

Received: 9 September 2014 / Accepted: 6 January 2015 / Published: 12 January 2015

\begin{abstract}
In metal cutting, the magnitude of the temperature at the tool-chip interface is a function of the cutting parameters. This temperature directly affects production; therefore, increased research on the role of cutting temperatures can lead to improved machining operations. In this study, tool temperature was estimated by simultaneous temperature measurement employing both a K-type thermocouple and an infrared radiation (IR) pyrometer to measure the tool-chip interface temperature. Due to the complexity of the machining processes, the integration of different measuring techniques was necessary in order to obtain consistent temperature data. The thermal analysis results were compared via the ANSYS finite element method. Experiments were carried out in dry machining using workpiece material of AISI 4140 alloy steel that was heat treated by an induction process to a hardness of 50 HRC. A PVD TiAlN-TiN-coated WNVG 080404-IC907 carbide insert was used during the turning process. The results showed that with increasing cutting speed, feed rate and depth of cut, the tool temperature increased; the cutting speed was found to be the most effective parameter in assessing the temperature rise. The heat distribution of the cutting tool, tool-chip interface and workpiece provided effective and useful data for the optimization of selected cutting parameters during orthogonal machining.
\end{abstract}


Keywords: tool temperature; thermocouple; machining; cutting speed; pyrometer

\section{Introduction}

During metal cutting, the magnitude of the temperature on the cutting edge is a function of the cutting parameters. This temperature directly affects the production. Heat generated during machining is affected by many events, including tool life, chip formation, surface quality, cutting forces, etc. Maximum heat occurs at the tool-chip interface. Thus, machinability can be improved by monitoring the cutting temperature of the tool.

Temperature estimation is one of the most difficult and complicated procedures in metal cutting operations. Due to the complexity of the various events taking place at the point of contact between the tool and workpiece, developing a model for measuring the temperature is an extremely difficult process. Consequently, accurate and repeatable temperature prediction still remains a challenge due to this complexity of the contact phenomena [1]. It is quite difficult to measure the temperature because the heat in the region is very close to the cutting edge. Due to the lack of sufficient experimental data, it is not possible to verify a mathematical model; however, numerous attempts have been made to measure the temperature in machining operations [2].

Lowen and Shaw [3] developed an analytical prediction model for the measurement of cutting temperatures during machining. They concluded that the cutting temperature is the function of cutting speed and feed rate. They specified the average cutting speed as:

$$
\Theta \mathrm{t}=V^{0.5} f^{0.3}
$$

where $\Theta \mathrm{t}$ is the average cutting temperature, $V$ is the cutting speed and $f$ is the feed rate.

Temperature measurement techniques include thermocoupling with an embedded tool-chip pair, measurement of infrared radiation (pyrometers, infrared photography, etc.) and the use of thermo-sensitive paint, as well as metallography based on metal microstructure or microhardness variations, measurement of temper colour, and the use of thermal cameras. Each technique has its own advantages and limitations depending on the physical measurement [4-7].

Thermocouples are one of the most widely used experimental methods for measuring the temperature in machining. Thermocouples are conductive, inexpensive, can be operated over a wide temperature range and can be easily applied; however, they only measures the mean temperature over the entire contact area of the tool and the workpiece. Stephenson stated that, based on this measurement technique using thermocouples, the average electromotor force (emf) is in the tool-workpiece interface [8]. Grzesik [9] investigated the influence of the tool-work interface temperature when machining AISI 1045 and AISI 304 using coated tools. A standard K-type thermocouple inserted into the workpiece was used to measure the interface temperature. The friction on the flank face had a great influence on the heat generated at a cutting speed of approximately $200 \mathrm{~m} / \mathrm{min}$. Cotterm [10] measured the machined surface temperatures with two thermocouples inserted into the workpiece when machining aluminum 6082-T6. The results indicated that an increase in the cutting speed led to a decrease in the cutting forces and the machined surface temperatures. This reduction in the temperature was attributed to the higher metal removal rate that resulted in more heat being carried away by the chip. 
Ay and Yang [11] used a technique with K-type thermocouples to analyze the temperature variations in carbide inserts when cutting various materials such as copper, cast iron, aluminum 6061 and AISI 1045 steel. They observed that oscillations in the temperatures at locations near the cutting edge were more rigorous for the ductile materials and less so in the hard-machining materials. Yujing et al. [12] reported an experimental investigation of the influence of cutting parameters on cutting temperature in the milling of Ti6AI4V by applying a semi-artificial thermocouple. Analysis results showed that the tool and workpiece temperature performed in a similar rising trend with the increase of cutting parameters including cutting speed, feed rate, radial feed, and axial feed, and that their degrees of influence decreased successively. Krishna et al. [13] investigated temperature prediction in the orthogonal machining of $\mathrm{AI} / \mathrm{SiCp}$ composites. Using a thermocouple, experiments were conducted to measure the temperature along the cutting tool edge at various cutting speeds and depths of cut, keeping the feed rate constant, while turning with a K-20 carbide cutting tool. An analysis of the steady state heat transfer was carried out and the temperature distribution at the cutting edge, shear zone, and interface regions was reported.

In addition to thermocouples, IR techniques are probably the second most common method for measuring temperatures in machining. In the IR technique, the surface temperature of the body is measured based on its emitted thermal energy [14]. In this technique, the radiation from the tool, the workpiece and the chip is measured to establish the temperature on the outside surfaces of these regions [15]. Radiation techniques are contactless methods for measuring the surface temperature of a body based on its emitted thermal energy. This technique is possibly the most suitable in turning, where high temperatures can be easily captured, as there is no direct contact with the heat source. On the other hand, chip obstruction makes it difficult to measure the temperature at the tool-chip interface [2]. Lin et al. [16] used an infrared pyrometer to measure the tool-chip temperature for carbide and ceramic tools at a cutting speed of $600 \mathrm{~m} / \mathrm{min}$. Dewes et al. [17] employed an IR camera and the thermocouple technique to measure the chip temperature when machining H13 hardened steel in high-speed machining. In a study to compare the heat flow through brazed and bonded tools, an IR camera was used by Darwish et al. [18] to measure the tool-chip interface temperature in orthogonal cutting tests. Young [19] used an IR camera to measure the temperature of the chip back section and the interface temperature in the orthogonal cutting of AISI 1045 steel.

The influence of cutting parameters on tool temperature has been examined in other studies such as that of Chu and Wallbank in 1998, where a relationship was established between the cutting temperature and the cutting parameters for a specific range of cutting speeds and feed rates. The relationship of the workpiece temperature with the cutting parameters was established and the results showed that the temperature correlated well with the cutting speed and the feed rate, but had little effect on the nose radius [20]. Liang et al. [21] developed a three-dimensional inverse heat conduction procedure that was proposed to quantitatively determine the steady-state tool-chip interface temperature in dry turning. The infrared method was utilized to measure the temperature on the rake face of the insert during the transient cooling process after the feed motion was halted. With the experimentally measured temperature data, the 3-D heat conduction model of the cutter and an optimization scheme were used to solve the effective heat flux on the tool-chip interface and the interface temperature during turning. Zgorniak and Grdulska [22] measured the temperature distribution in the cutting zone during the end milling operation of magnesium alloy AZ91HP by employing the IR measurement technique. In summary, it is possible to observe 
temperature distribution and even monitor the temperature of chips created during a manufacturing process; however, the measurement of the temperature in machining is still a challenge that requires unique solutions.

In this study, the most widely used embedded K-type thermocouple and an infrared pyrometer were selected for the measuring of tool and the tool-chip interface temperatures during orthogonal metal cutting. The effects of the cutting speed, the feed rate and the depth of cut on the temperatures were observed. The heat distribution in the cutting tool, tool-chip interface and workpiece provided useful information about the optimization of selected cutting parameters.

\section{Temperatures in Metal Cutting}

In the cutting process, nearly all of the energy dissipated in plastic deformation is converted into heat that, in turn, raises the temperature in the cutting zone. Because heat generation is closely related to plastic deformation and friction, three main sources of heat can be specified when cutting: (1) plastic deformation by shearing in the primary shear zone; (2) friction on the cutting face; and (3) friction between the chip and the tool on the tool flank.

Temperature causes dimensional errors on the machined surface. The cutting tool elongates as a result of the increased temperature, and the position of the cutting tool edge shifts toward the machined surface, resulting in a dimensional error of approximately $0.01-0.02 \mathrm{~mm}$. Because the processes of thermal generation, dissipation, and solid body thermal deformation are all transient, some time is required to achieve a steady-state condition. Heat is mostly dissipated by the discarded chip, which carries away approximately $60 \%-80 \%$ of the total heat. The workpiece acts as a heat sink drawing $10 \%-20 \%$ of the heat away, and the cutting tool draws away $\sim 10 \%$ of the heat. The balance of the heat generation and the heat dissipation in metal cutting is shown in Figure 1.
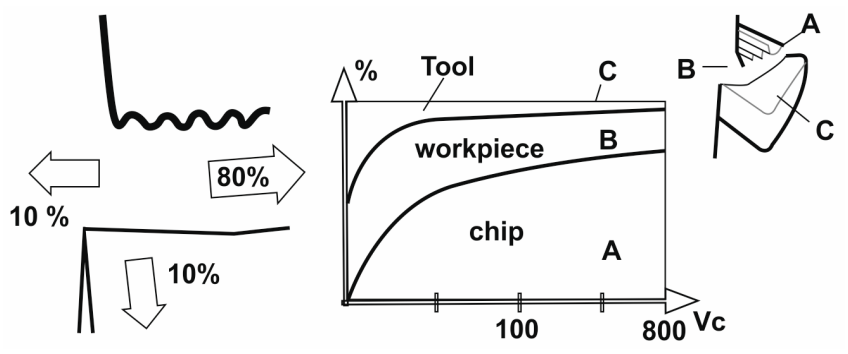

Figure 1. The balance of heat generation and heat dissipation in metal cutting [23].

The cutting temperature is not constant throughout the tool, the chip or the workpiece. It can be observed that the maximum temperature is developed not on the very cutting edge, but at the tool rake, some distance away from the cutting edge. The temperature field in the cutting zones is shown in Figure 2.

The heat generated during the metal cutting process is due to the plastic deformation energy that transforms itself into the form of heat. The heat generation rate, Q (W), is given by Sata and Takeuchi $[25,26]$ as:

$$
\mathrm{Q}=1.68 a f^{0.15} V^{0.85}
$$

where $a$ is the depth of cut $(\mathrm{mm}), f$ is the feed rate $(\mathrm{mm} / \mathrm{rev})$, and $V$ is the cutting speed $(\mathrm{m} / \mathrm{min})$. 


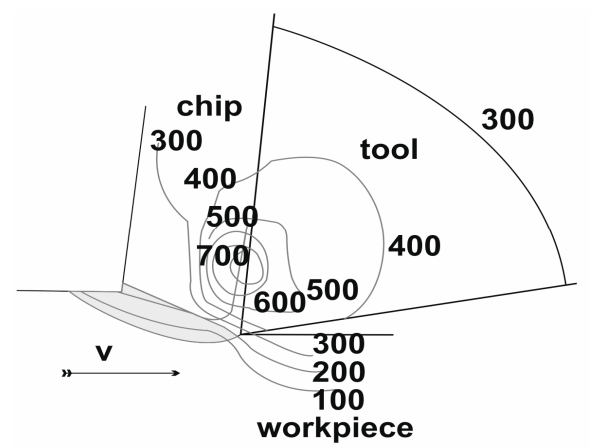

Figure 2. Co-temperature curves [24].

\section{Experimental Conditions}

In this study, two methods of tool temperature evaluation are presented: the placement of a K-type thermocouple on the tool and the use of an infrared pyrometer. A schematic view of the experimental setup is shown in Figure 3 and experimental conditions are recorded in Table 1. The machining process was performed using a NR 2020K-08 tool holder and a PVD TiAlN-TiN-coated WNVG 080404-IC907 carbide insert. The workpiece material was an AISI 4140 alloy steel. The chemical composition of the workpiece material is shown in Table 2 .

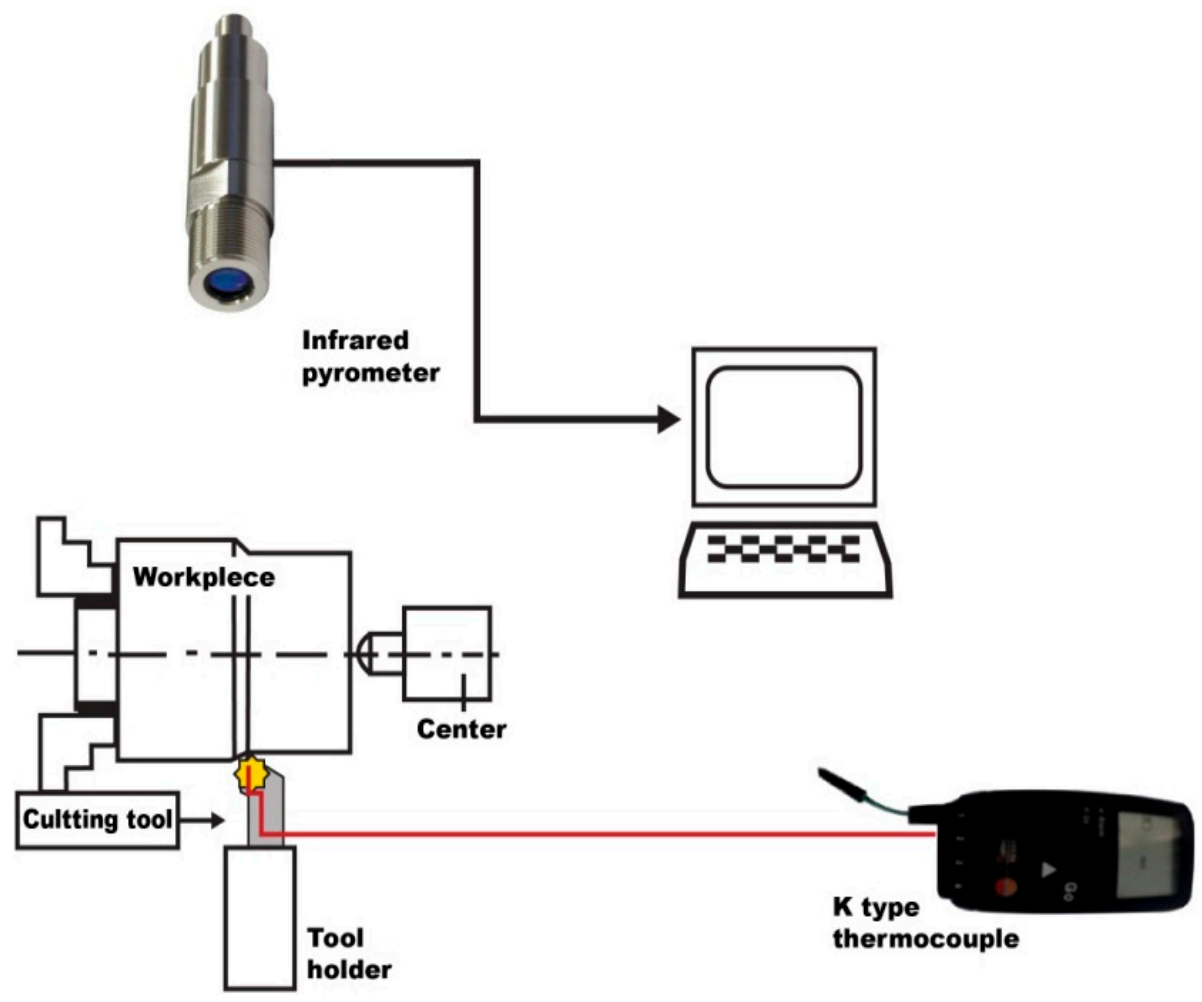

Figure 3. Schematic view of the experimental setup.

Cylindrical workpieces $(\varnothing 45 \times 300 \mathrm{~mm})$ were fixed between the chuck and the tailstock and were pre-machined using a separate insert. The samples were heat treated by induction hardening and a hardness of $50 \mathrm{HRC}$ was maintained. The samples were then solution heat treated and oil quenched to achieve proper hardness. After the heat treatment, the material was normalized. 
Table 1. Experimental conditions.

\begin{tabular}{cc}
\hline Machine tool & Harrison M300 \\
Work specimen's materials & AISI 4140 alloy steel \\
Size & PVD coated carbide TiAIN-TiN cutting insert, WNVG 080404 \\
Cutting tools & DWLNR 2020K-08 \\
Tool holder & $0.4 \mathrm{~mm}$ \\
Working tool geometry & Inclination angle:-6, rake angle:-6, clearance angle: 6 , edge angle: 80 \\
Principal nose radius & Optris CF4 infrared pyrometer \\
Measurement temperatures & K-type thermocouple, TESTO 177 \\
Thermocouple & $76 \mathrm{~m} / \mathrm{min}, 114 \mathrm{~m} / \mathrm{min}, 170 \mathrm{~m} / \mathrm{min}$ \\
Cutting speed, $\mathrm{V}$ & $0.05 \mathrm{~mm} / \mathrm{rev}, 0.08 \mathrm{~mm} / \mathrm{rev}, 0.12 \mathrm{~mm} / \mathrm{rev}$ \\
Feed rate, $\mathrm{f}$ & $0.40 \mathrm{~mm}, 0.60 \mathrm{~mm}$ \\
Depth of cut, a & Dry \\
Environment &
\end{tabular}

Table 2. Chemical composition of AISI 4140 alloy steel (vol\%).

\begin{tabular}{cccccccc}
\hline $\mathbf{C}$ & $\mathbf{C r}$ & $\mathbf{N i}$ & $\mathbf{M n}$ & $\mathbf{P}$ & $\mathbf{S}$ & $\mathbf{S i}$ & $\mathbf{M o}$ \\
\hline 0.38 & 0.80 & 9.58 & 0.75 & 0.035 & 0.04 & 0.15 & 0.15 \\
\hline
\end{tabular}

\subsection{Infrared Pyrometer}

The radiation technique uses contactless methods to measure the surface temperature of the body based on its emitted thermal energy. This technique is likely the most suitable in turning where high temperatures can be captured easily as there is no direct contact with the heat source. During the experiments, the tool-chip interface temperature was measured using an Optris CF4 infrared pyrometer, the specifications of which are shown in Table 3. To measure the temperature, the infrared pyrometer was placed precisely $45 \mathrm{~cm}$ above the tool rake face. Five signals were applied per second for the various cutting parameters. The size of the measurement spot was $1.5 \mathrm{~mm}$, which corresponded to the distance to the measurement surface of $0.6 \mathrm{~mm}$. The pyrometer had a response time of $200 \mathrm{~ms}$. The selected measurement site was on the insert rake face at $1 \mathrm{~mm}$ from the cutting edge and just beside the leading edge in order to avoid chip obstruction. With the experimental apparatus for tool-chip interface temperature measurements using the infrared system with an IR (infrared radiation) pyrometer, the target image temperature ranged from 385 to $1600{ }^{\circ} \mathrm{C}$. The minimum resolvable temperature difference was approximately $\pm 2^{\circ}$ or $\pm 0.2 \%$. System accuracy (at an ambient temperature of $23 \pm 5{ }^{\circ} \mathrm{C}$ ) was $\pm(0.3 \%$ of reading $+2{ }^{\circ} \mathrm{C}$ ). The IR pyrometer was presumed to be more suitable as it is more accurate for use in turning processes where high temperatures can be captured easily as there is no directed contact with the heat source.

It is obvious that the maximum temperature zone was somewhat distant from the cutting edge, which theoretically corresponds to the zone of maximum wear of the tool, i.e., the zone of maximal tool wear coincides with the maximum temperature zone. The contact area on the rake face is usually defined due to the fact that there is no universal method of measuring and predicting the area of contact between the tool and the chip. The contact area is in most cases controlled by the length of contact. The width of the region of contact is usually about the same size as the depth of cut. 
Table 3. Specifications of the IR (infrared radiation) pyrometer.

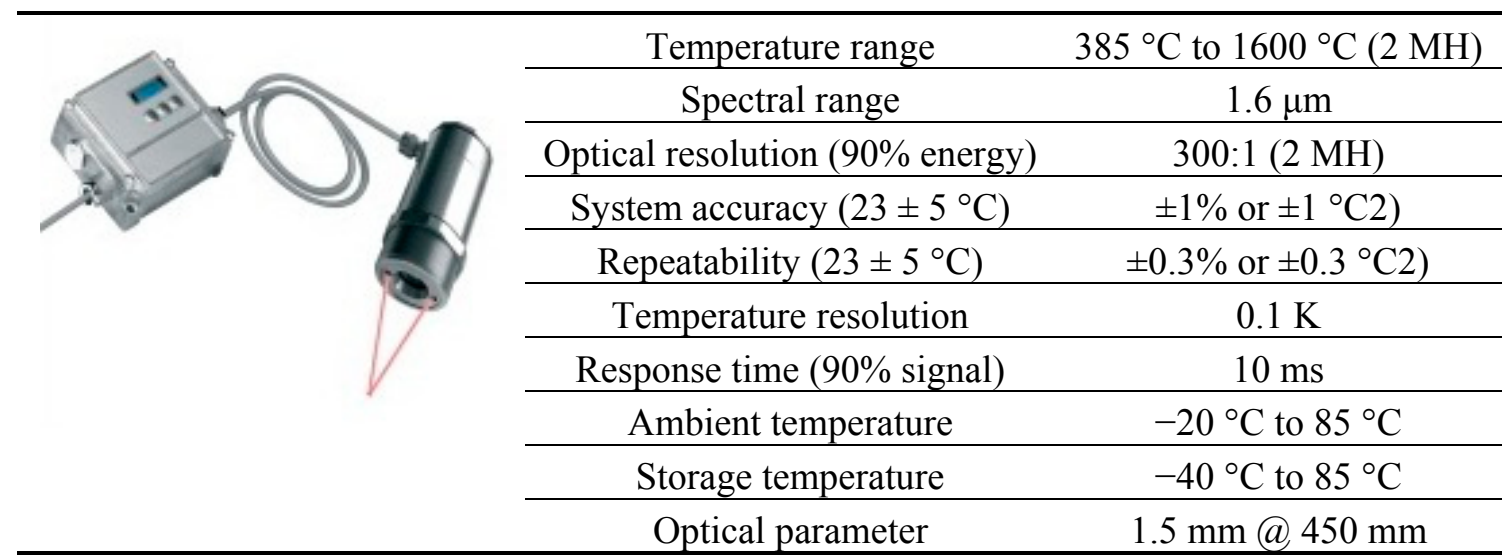

\subsubsection{Construction and Operation of the Infrared Pyrometer}

A block diagram showing the general construction of an infrared pyrometer can be seen in Figure 4 . By use of input optics, the emitted object radiation was focused onto an infrared detector. The detector generates a corresponding electrical signal which is then amplified and may be used for further processing. Digital signal processing transforms the signal into an output value proportional to the object temperature. The temperature result is shown on a display. Consequently, the temperature of the measured object is mainly generated in three steps: (1) transformation of the received infrared radiation into an electrical signal; (2) compensation of background radiation from pyrometer and object; and (3) linearization and output of temperature information [27].

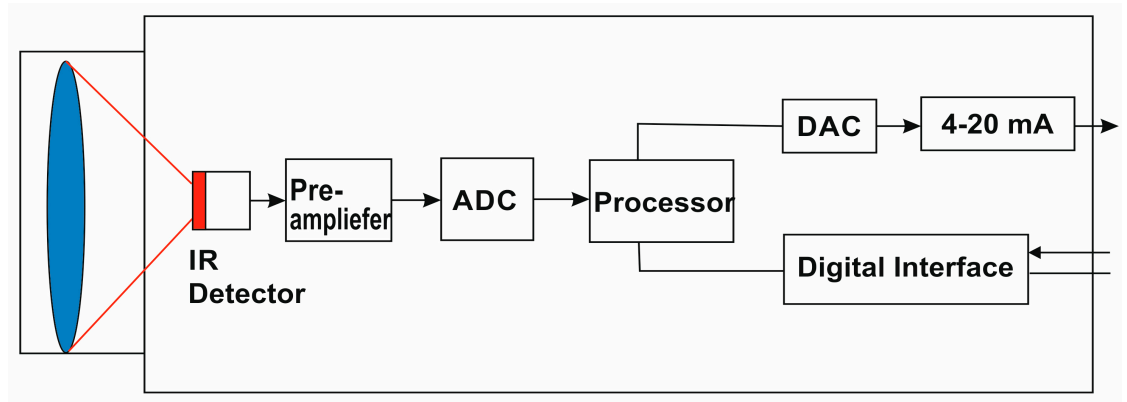

Figure 4. Block diagram of an IR pyrometer.

\subsubsection{Calibration of the Infrared Pyrometer}

Emissivity is the measure of the ability of an object to absorb, transmit and emit infrared energy. Emitted energy indicates the temperature of the object. It can have values ranging from 0 (shiny mirror) to 1.0 (black body). If a value of emissivity is higher than the actual set value, the output will read low, provided that the target temperature is above the ambient one. The emissivity of the material is the crucial parameter for thermal radiative heat transfer. The emissivities of an AISI 4140 alloy steel were measured as a function of the surface temperature. In the literature, the recommended emissivity value for AISI 4140 alloy steel is between 0.50 and 0.75 [28]. For an accurate measurement of the cutting temperature, different emissive values (in the range of $0.45-0.85$ ) were tried in order to adjust the accuracy of the temperatures at constant cutting parameters. Figure 5 shows the temperature measurements at various 
emissivity values. The standard procedure was applied during the experiments to ensure reliable and repeatable results. The infrared pyrometer was calibrated as a standard device prior to its use to determine the transfer factors. To machine AISI 4140 alloy steel using TiAIN-TiN-coated tungsten carbide, the emissivity value of 0.60 was identified for a range of $385^{\circ} \mathrm{C}$ to $600{ }^{\circ} \mathrm{C}$.

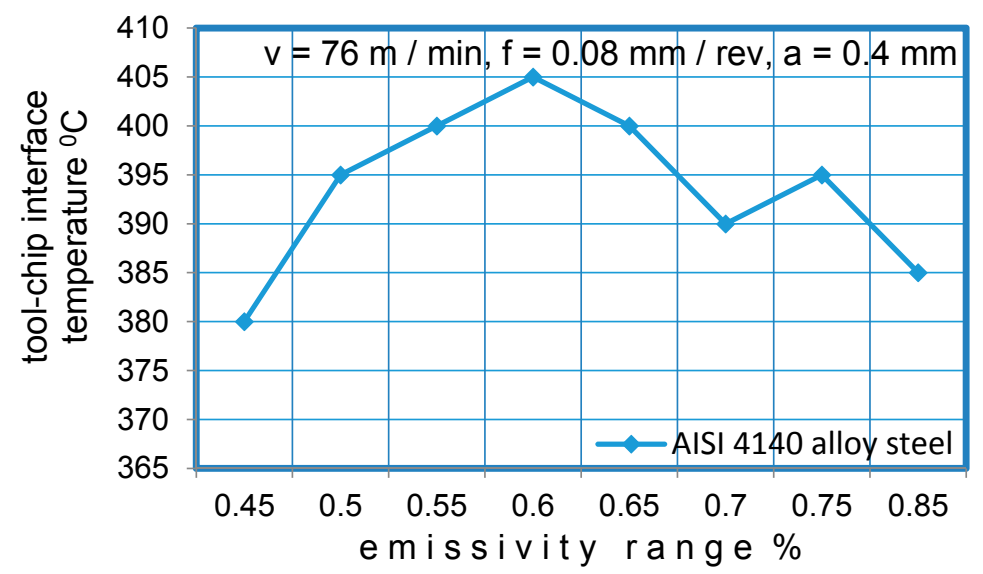

Figure 5. Emissivity range of the IR pyrometer.

\subsection{The Thermocouple}

The principle of temperature measurement by a thermocouple is that when two different metals come in contact, if these parts, called the hot and the cold junctions, are maintained at two different temperatures, an electromotive force (emf) is produced across these two junctions. The emf generated is a function of the materials used for the thermocouple as well as the temperatures of the junctions. In machining applications, a thermoelectric emf is generated between the tool and the workpiece [29]. For this study, the tool temperature was measured using a K-type thermocouple. In Figure 6, a K-Type thermocouple display is presented. The highest cutting temperature on the insert was observed $1 \mathrm{~mm}$ below the cutting edge. Therefore, the thermocouple set was mounted $1 \mathrm{~mm}$ away from the front surface and $1 \mathrm{~mm}$ from the upper surface of the cutting edge. Figure 7 displays the position of the thermocouple. Considering the depth of cut, there were some difficulties in mounting the thermocouple. These difficulties occurred because the tool-chip contact point varies continuously during cutting as a result of the variations in the cutting speed, the feed rate and the depth of cut. The thermocouple diameter was $0.5 \mathrm{~mm}$ and the temperature measurement range was $-195{ }^{\circ} \mathrm{C}$ to $1100{ }^{\circ} \mathrm{C}$. The mounting of a thermocouple is shown in Figure 8. For the study, the accuracy of the tool temperature measurements using the K-type thermocouple data acquisition system was $\pm 2.5^{\circ} \mathrm{C}$ or $\pm 1 \%$.

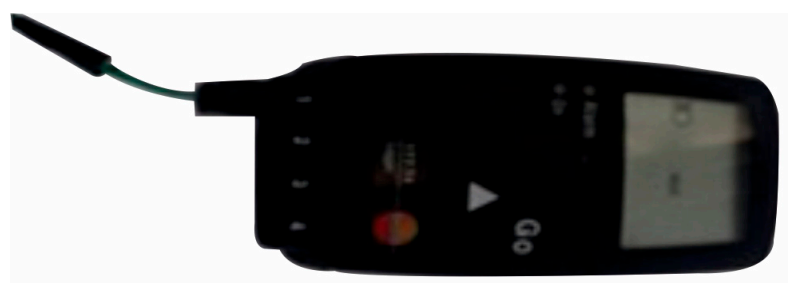

Figure 6. K-Type thermocouple display. 


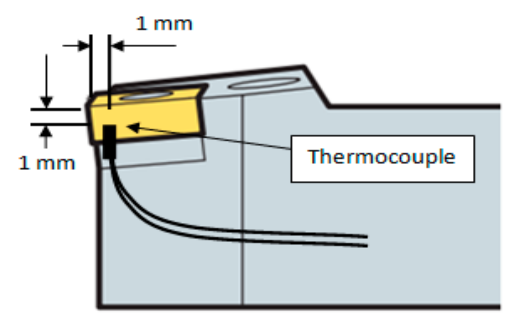

Figure 7. Position of thermocouple.

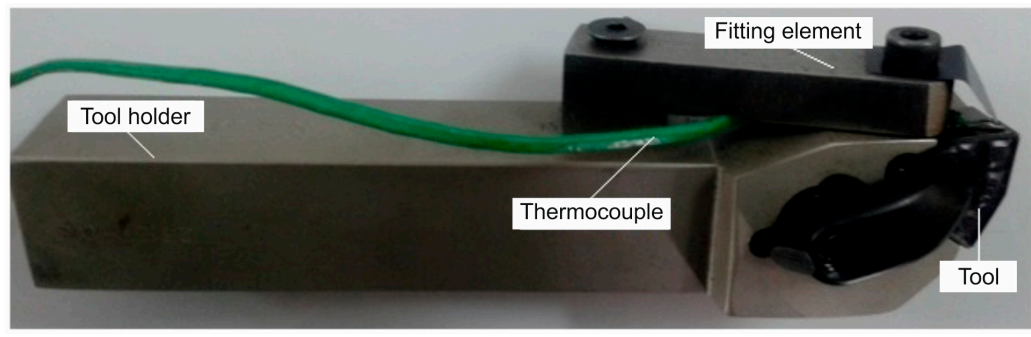

Figure 8. Mounting of thermocouple onto the tool holder.

For the tool temperature measurements, a thermocouple with a TESTO 177 thermometer having four temperature inputs was used. In Figure 9, the thermocouple and the IR pyrometer connections on the tool holder are shown.

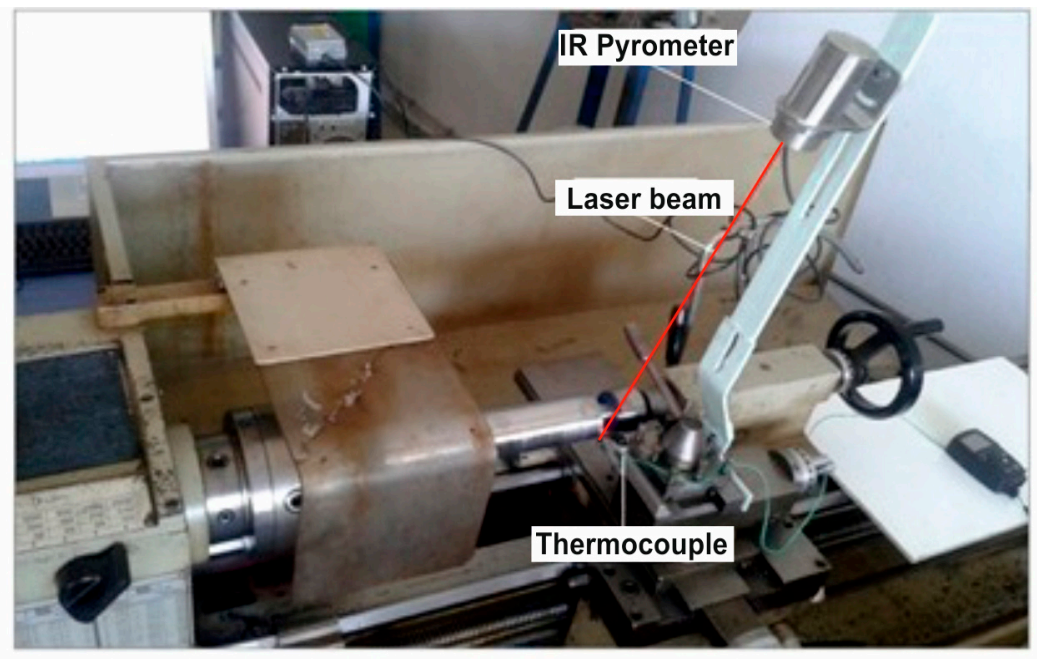

Figure 9. Thermocouple and IR pyrometer connections onto the lathe.

\section{Methods}

\subsection{Experimental Procedure}

The Taguchi L18 $(21 \times 37)$ method was used for the determination of optimum control factors. Low, medium and high cutting parameters were selected for the experiments. In the selection of these parameters, the tool manufacturers' recommendations and the machine tool capacity were taken into consideration. There were $18(3 \times 3 \times 2)$ combinations of the turning tests in total which were all carried out to complete the experiments. The experimental conditions are shown in Table 4. 
Table 4. Machining parameters and their levels.

\begin{tabular}{cccc}
\hline \multirow{2}{*}{ Parameters } & \multicolumn{3}{c}{ Levels } \\
\cline { 2 - 4 } & $\mathbf{1}$ & $\mathbf{2}$ & $\mathbf{3}$ \\
\hline Cutting speed $V,(\mathrm{~m} / \mathrm{min})$ & 76 & 114 & 170 \\
Feed rate $f,(\mathrm{~mm} / \mathrm{rev})$ & 0.05 & 0.08 & 0.12 \\
Depth of cut $a,(\mathrm{~mm})$ & 0.40 & 0.60 & \\
\hline
\end{tabular}

\subsection{IR Pyrometer Measurement of Tool-Chip Interface Temperature}

In this study, an infrared pyrometer, the Optris CF4, was used to measure the tool-chip interface temperature. The maximum temperature (approximately $525^{\circ} \mathrm{C}$ ) was recorded around the cutting zone. A total of 18 trials were conducted throughout these experiments and brand new inserts were used for each temperature measurement. Hence, the cutting temperature increased as the cutting speed, the feed rate and the depth of cut increased. During the experiments, in order to measure the tool-chip interface temperatures with the IR pyrometer, five measurements were taken per second and the measurements were averaged for each of the cutting parameters. The experiments were repeated three times. During the measurement process, because the cutting zone was very small and obstructed by chips, some difficulties were encountered due to occasional blockage.

\subsection{Thermocouple Measurement of Tool Temperature}

In the measurement of the temperature with the thermocouple, some difficulties were encountered in the region of the assembly closest to the cutting zones. To avoid this situation, a special apparatus was designed and manufactured for the thermocouple connection to the tool holder. The thermocouple measurements were recorded every five seconds. The measurements were repeated three times for the same cutting parameters and the measurement results were averaged.

\section{Analysis of Experimental Results}

This paper presents a combination of two techniques of temperature measurement used simultaneously in order to evaluate the temperature distribution in metal cutting operations. It was observed that the application of simultaneous measurements (both chip temperature and tool temperature) in machining is unique and there are very few related works encountered in the literature.

Not much information is to be found in the literature dealing with heat distribution on the chip, tool and workpiece. Only a few ratios are given and these ratios are highly dependent on cutting parameters. There are not many works dealing with the influence of cutting speed and its association with heat distribution.

Some practical difficulties are also discussed in this paper. The difficulty of direct measurement of localized high temperatures at the contact interface between the cutting tool and the sliding chip occurred because the site was constantly obscured throughout the cutting. Chip obstruction made it difficult to measure the temperature.

The use of thermocouples to measure the tool-chip interface temperature is not possible due to the blocking of the cutting chips and the difficulty of mounting the thermocouples precisely to the shear zone. Therefore, an IR pyrometer is required to measure the tool-chip interface temperature. 
In the metal cutting industry, heat is generally dissipated by the discarded chip, which carries away approximately $70 \%-80 \%$ of the total heat. The workpiece acts as a heat sink drawing $10 \%-20 \%$ of the heat away and the cutting tool draws away $\sim 10 \%$ of the heat.

The heat distribution of the cutting tool, tool-chip interface and workpiece can provide useful information about the optimization of selected cutting parameters. Therefore, the relationship between the cutting parameters and heat distribution needs to be precisely determined. The aim of the present paper was to establish this relationship. Simultaneous temperature measurements were made during the experiments and the experimental results are given in Table 5.

Table 5. Experimental results.

\begin{tabular}{ccccccc}
\hline No & $\begin{array}{c}\mathbf{A} \\
{[\mathbf{m m}]}\end{array}$ & $\begin{array}{c}\mathbf{V} \\
{[\mathbf{m} / \mathbf{m i n}]}\end{array}$ & $\begin{array}{c}\mathbf{f} \\
{[\mathbf{m m} / \mathbf{r e v}]}\end{array}$ & $\begin{array}{c}\text { Tool Temperature }\left[{ }^{\circ} \mathbf{C}\right] \\
\text { (Thermocouple) }\end{array}$ & $\begin{array}{c}\text { Tool-Chip Interface } \\
\text { Temperature }\left[{ }^{\circ} \mathbf{C}\right] \\
\text { (IR Pyrometer) }\end{array}$ & $\begin{array}{c}\text { Tool-Chip Interface/Tool } \\
\text { Temperature Percent } \\
\text { Contribution (\%) }\end{array}$ \\
\hline 1 & 0.4 & 76 & 0.05 & 57 & 410 & 0.139 \\
2 & 0.4 & 76 & 0.08 & 66 & 405 & 0.162 \\
3 & 0.4 & 76 & 0.12 & 72 & 410 & 0.175 \\
4 & 0.4 & 114 & 0.05 & 65 & 460 & 0.141 \\
5 & 0.4 & 114 & 0.08 & 61 & 465 & 0.131 \\
6 & 0.4 & 114 & 0.12 & 67 & 445 & 0.150 \\
7 & 0.4 & 170 & 0.05 & 65 & 520 & 0.125 \\
8 & 0.4 & 170 & 0.08 & 67 & 500 & 0.134 \\
9 & 0.4 & 170 & 0.12 & 71 & 475 & 0.149 \\
10 & 0.6 & 76 & 0.05 & 72 & 400 & 0.180 \\
11 & 0.6 & 76 & 0.08 & 80 & 390 & 0.205 \\
12 & 0.6 & 76 & 0.12 & 76 & 395 & 0.192 \\
13 & 0.6 & 114 & 0.05 & 80 & 430 & 0.186 \\
14 & 0.6 & 114 & 0.08 & 75 & 435 & 0.172 \\
15 & 0.6 & 114 & 0.12 & 83 & 420 & 0.198 \\
16 & 0.6 & 170 & 0.05 & 81 & 485 & 0.167 \\
17 & 0.6 & 170 & 0.08 & 67 & 525 & 0.128 \\
18 & 0.6 & 170 & 0.12 & 69 & 480 & 0.143 \\
\hline
\end{tabular}

During the machining process, there are many advantages to using the multi-sensor approach as measuring the tool and tool-chip interface temperatures. This method can provide extremely useful information as to whether or not the optimal cutting parameters have been selected by determining the ratio of the cutting tool temperature to the tool-chip interface temperature. Moreover, this method makes it possible to determine the optimum cutting parameters.

\section{Effect of Cutting Conditions on Temperature}

In the experiments, the influence of the cutting parameters such as cutting speed, feed rate and depth of cut on the cutting temperature of AISI 4140 was observed. The higher the cutting speed, the higher the tool-chip interface temperature increase, resulting in a significant temperature difference.

During the cutting process, an increase in the temperature was observed depending on the processing time. This was due to the tool wear and the increased friction at the cutting zone, which was taken into 
consideration in the tool temperature calculations. Figure 10 shows the variations of the tool temperature with the time at various cutting speeds and feed rates.
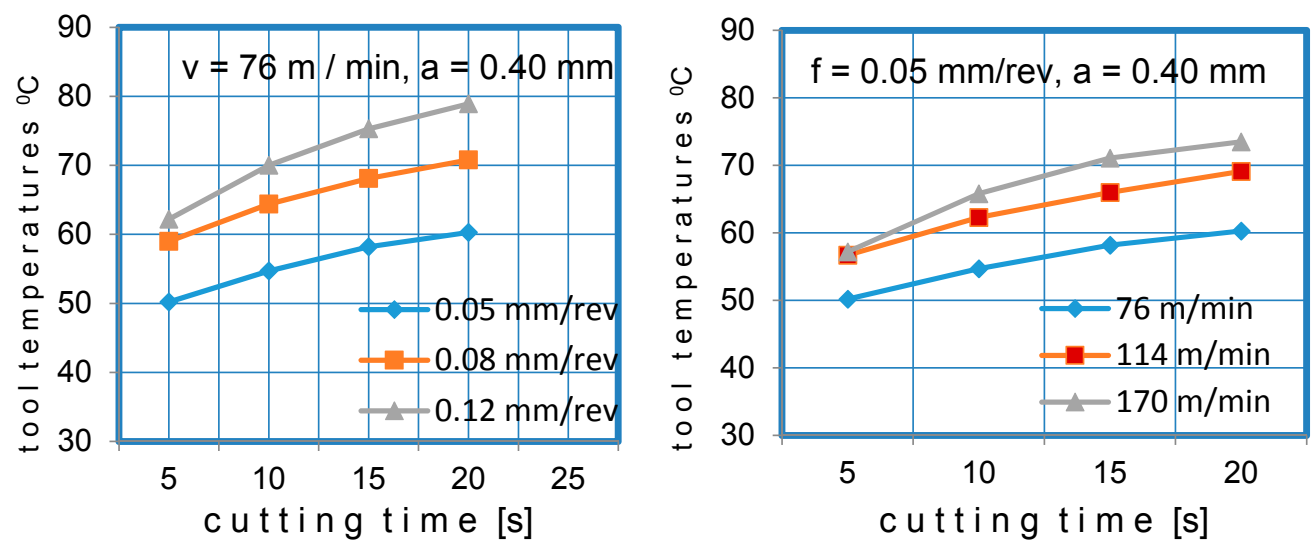

Figure 10. Change of tool temperature during the cutting process, depending on the time.

The cutting speed is the cutting parameter that affects tool life most. However, there are some positive effects of increasing the cutting speed (such as improvement in friction). During the metal cutting, a large amount of the heat was removed from the workpiece by the chip. As the cutting speed gets higher, more heat is removed, but the tool temperature increases as well (see Figure 1). Reducing the cutting speed increases the amount of heat flowing to the workpiece, which causes the temperature of the workpiece to rise. Although increase in cutting speed increases the temperatures abruptly, the feed rate has very little effect on the temperature rise. The variations of tool temperature and the tool-chip interface temperature with the cutting parameters are shown in Figure 11. It can be readily observed that the tool-chip interface temperature and the tool temperature rise with the increase in cutting speed.
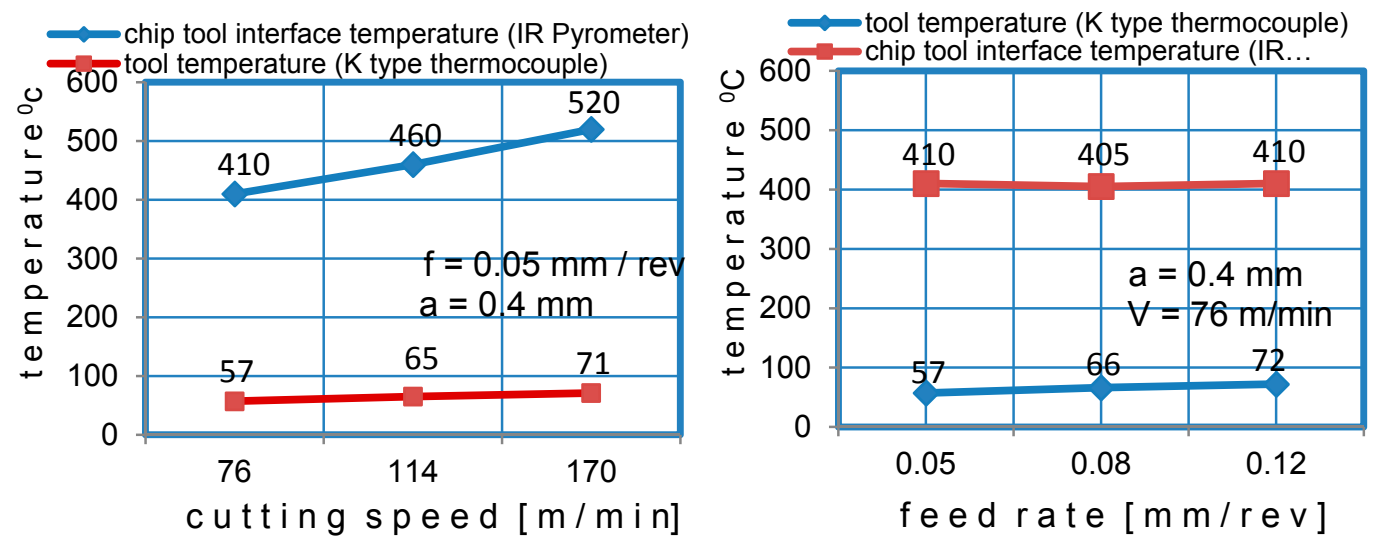

Figure 11. The influence of cutting speed and feed rate on temperatures.

During the experiments, PVD TiAlN-TiN-coated carbide inserts were used. The temperature increase in the tool is more limited compared to the increase in the tool-chip interface temperature due to the poor thermal conductivity of the coating material. The tool-chip temperature interface increase by $30 \%$ as the cutting speed increased; however, no significant temperature rise was observed for the feed rate. Both parameters had similar effects on the tool temperature. The influence of the feed rate and the cutting speed on the tool-chip interface temperature is shown in Figure 12. 

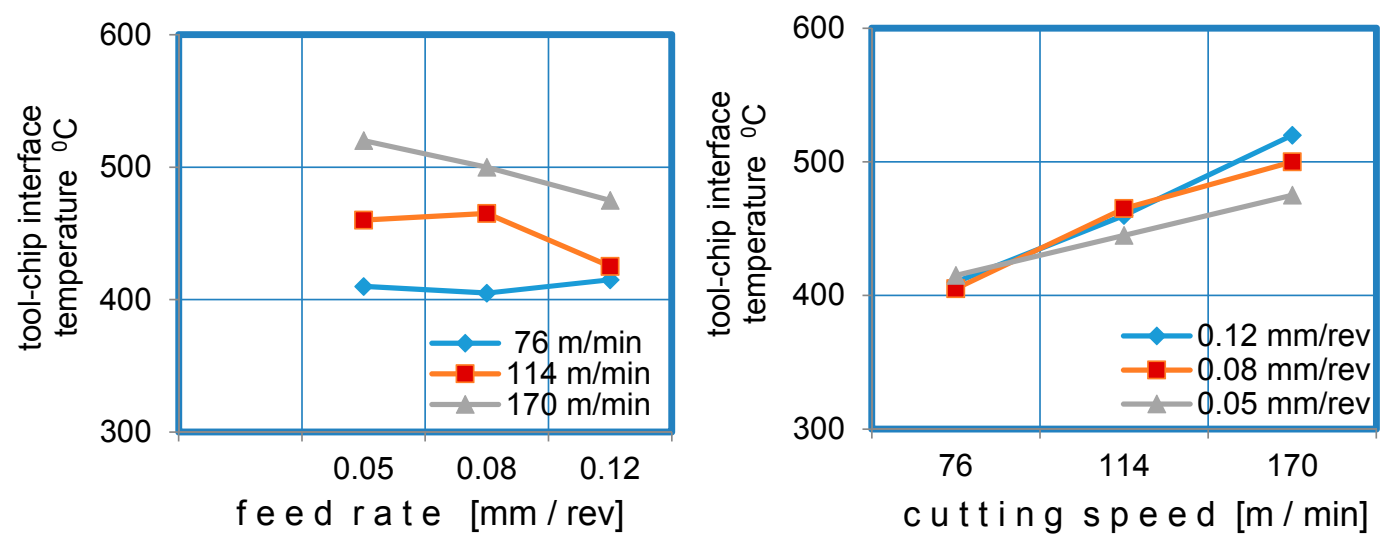

Figure 12. The influence of feed rate and cutting speed on tool-chip interface temperature.

The tool-chip interface temperatures rose with the increase in cutting speed, and the chip colour became darker due to the increasing disposal rate of the chips. Significant changes in the form and the curvature of the chips were also observed. Figure 13 shows the chip forms at different tool-chip interface temperatures and different cutting speeds.
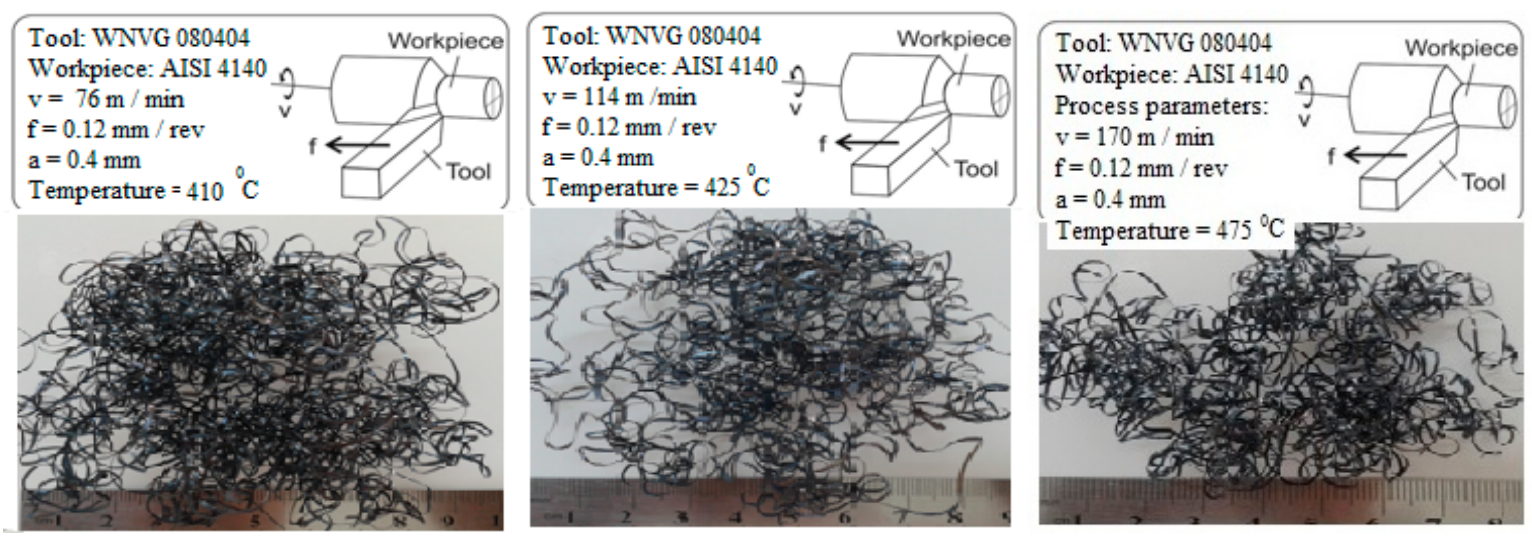

Figure 13. Chips form at different tool-chip interface temperatures and cutting speeds.

\section{Finite Element Simulation of Cutting Temperature}

Finite element analysis (FEA) is the most useful and accurate approach for the determination of field variables. This method is made possible by advancements in computing and computer processing powers and thus it has been used for almost all computer aided design methodologies in recent years. Applications range from deformation and stress analysis to field analysis of heat flux, fluid flow, magnetic flux, seepage and other flow problems. In this method of analysis, a complex region defining a continuum is disassembled into simple geometric shapes called finite elements.

Moreover, in order to verify the test results, it was essential to employ the FEM (finite element method). In this study, there was a good agreement between the test results and the FEM results. In this work, the application of FEM for thermal analysis of a single-point cutting tool in a turning operation is presented. Once the model for the determination of the temperature field for the single-point cutting tool was developed and verified using the experimental results, it was used to observe the effects of various 
parameters including the cutting parameters, the tool geometry, the tool material, the distance of the sensors from the cutting region and the rate of heat dissipation.

\section{Finite Element Model}

A 3-D finite element simulation model was developed for simulation of the temperature based on the estimated heat over the tool-chip contact area. The real geometry of the cutting tool and the tool holder model were designed to achieve more realistic and accurate simulation results. The maximum temperature of $520{ }^{\circ} \mathrm{C}$ was recorded at the tool-chip interface. The heat converted from the work of plastic deformation and friction was assumed to be the same for the case in the simulations. The geometry and the material properties of the tool and the tool holder are listed in Table 6.

The convective heat transfer coefficient for the top surface of the cutting tool on the tool holder was set at $20 \mathrm{~W} / \mathrm{m}^{2 \circ} \mathrm{C}$ and applied to the top corner of the insert, where the heating zone on the corner was held constant: $\mathrm{A}=\pi \times 1 \mathrm{~mm}^{2} / 4=0.78 \times 10^{-6} \mathrm{~m}^{2}$. As for a typical cutting tool simulation, a heat flow (Q) of $17 \mathrm{~W}$ was used. The temperature near the heat source was observed to be $412{ }^{\circ} \mathrm{C}$.

Table 6. Input values of the FEA (finite element analysis) model for the cutting tool.

\begin{tabular}{cc}
\hline Tool holder width and height & $20.00 \mathrm{~mm}$ \\
Initial temperature & $25^{\circ} \mathrm{C}$ \\
Tool holder length & $120.00 \mathrm{~mm}$ \\
Insert thickness & $4.00 \mathrm{~mm}$ \\
Density of insert & $14,900 \mathrm{~kg} / \mathrm{m}^{3}$ \\
Thermal conductivity of insert & $36 \mathrm{~W} / \mathrm{m} \mathrm{K}$ \\
Specific heat of insert & $302 \mathrm{~J} / \mathrm{kg} \mathrm{K}$ \\
Density of tool holder & $7850 \mathrm{~kg} / \mathrm{m}^{3}$ \\
Thermal conductivity of tool holder & $16 \mathrm{~W} / \mathrm{m} \mathrm{K}$ \\
Specific heat of tool holder & $434 \mathrm{~J} / \mathrm{kg} \mathrm{K}$ \\
\hline
\end{tabular}

The thermal and the mechanical properties of the cutting insert and the tool holder material are given in Table 6. The transient thermal analysis was performed using an ANSYS commercial finite element code. The calculated heat flux applied to the tool-chip contact area on the rake face of the cutting insert was the basis of the thermal analysis. Figure 14 shows the tool-chip contact area on the cutting insert to which heat flux was applied. The boundary conditions applied on the finite element model can be seen in Figure 15. The calculated heat flow on the tool-chip interface was $17 \mathrm{~W}$. Other surfaces, except for the end of the tool holder, were set to be adiabatic and the end of the tool holder was set to the ambient temperature. The ambient temperatures considered were in the range of $20{ }^{\circ} \mathrm{C}$ to $30{ }^{\circ} \mathrm{C}$. The adiabatic boundary condition of the rest of the exposed surface was based on the boundary conditions set by Tay et al. [30].

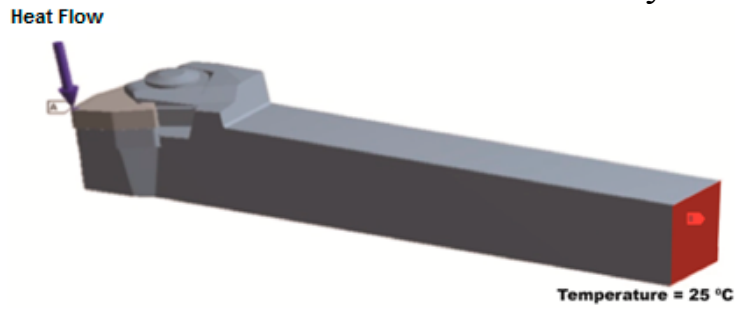

Figure 14. Boundary conditions. 


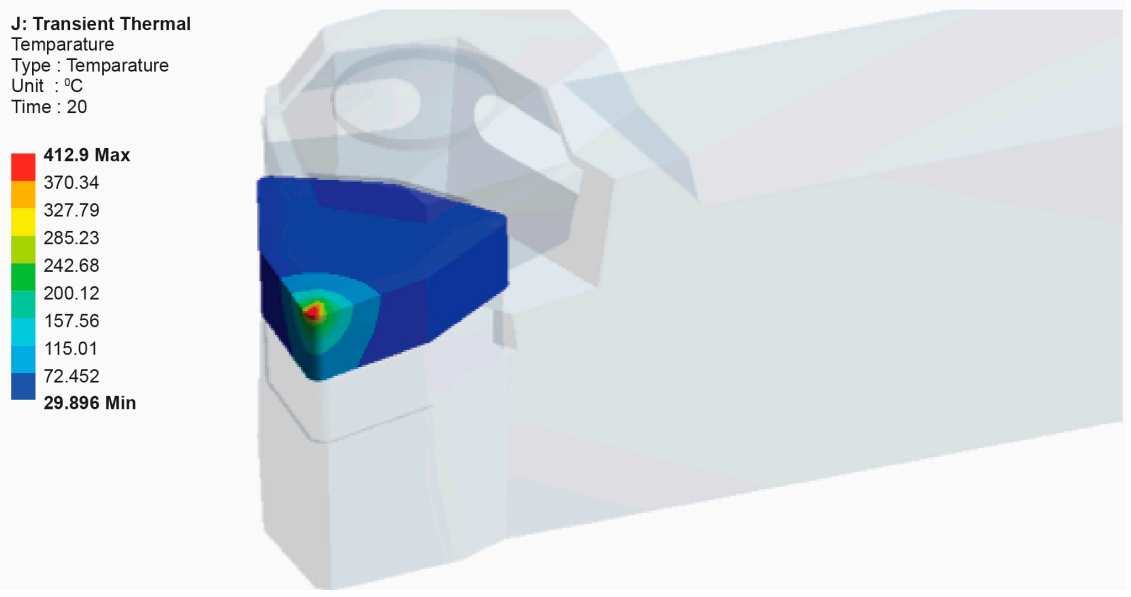

Figure 15. Temperature distribution on the cutting insert.

It is possible to evaluate the heat distribution into the cutting tool by employing a FEM model, reducing the available heat flux until the simulated temperature matches with the experimentally measured temperature. Figure 16 shows the temperature distribution of between $29.89{ }^{\circ} \mathrm{C}$ and $412.9{ }^{\circ} \mathrm{C}$ on the tool-chip interface as well as the temperature distribution along the $12 \mathrm{~mm}$ path that starts from the tool-chip interface.

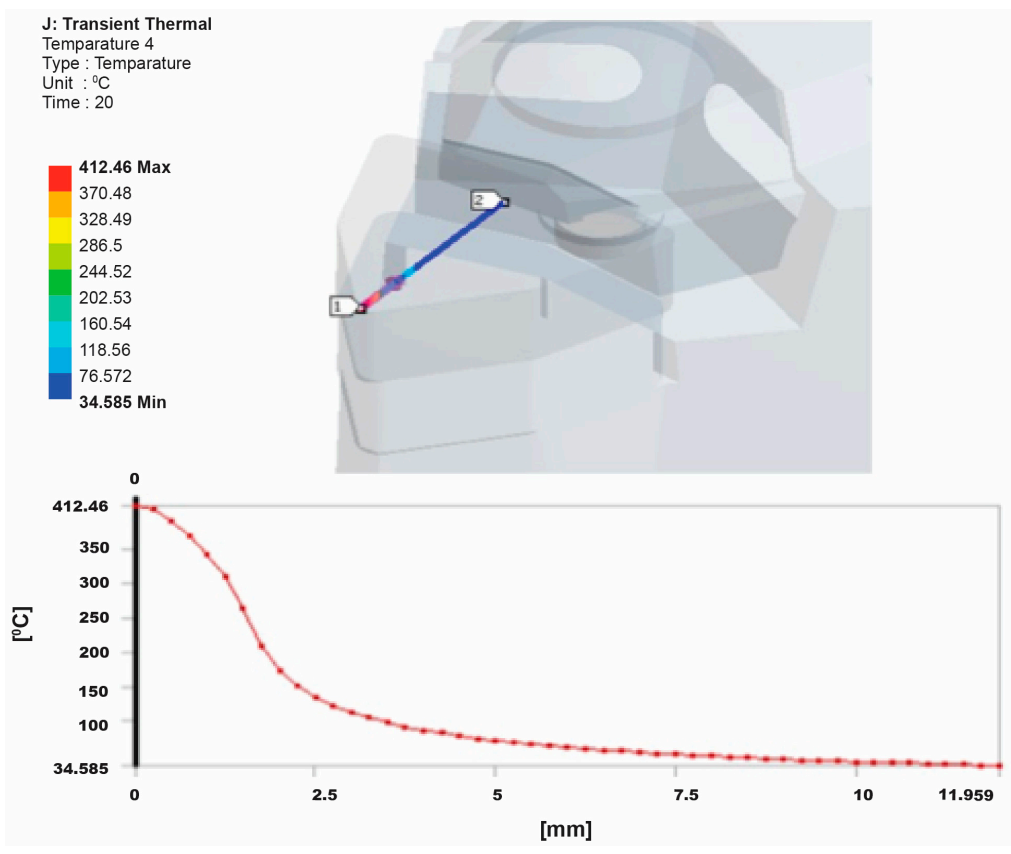

Figure 16. Temperature distribution on the path from the tool-chip interface.

The temperature results obtained from the experimental tests were $410{ }^{\circ} \mathrm{C}$ on the tool-chip interface and $57{ }^{\circ} \mathrm{C}$ near the tool-chip interface for a $0.4 \mathrm{~mm}$ cutting depth, a $76 \mathrm{~m} / \mathrm{min}$ cutting velocity and a $0.05 \mathrm{~mm} / \mathrm{rev}$ feed rate. For the verification and confirmation of the experimental results, the temperature distribution was simulated by using FEA. Comparison of the temperature values obtained by the finite element results and the experimental results showed good agreement. Figure 17 shows the temperature probe values for some locations. 


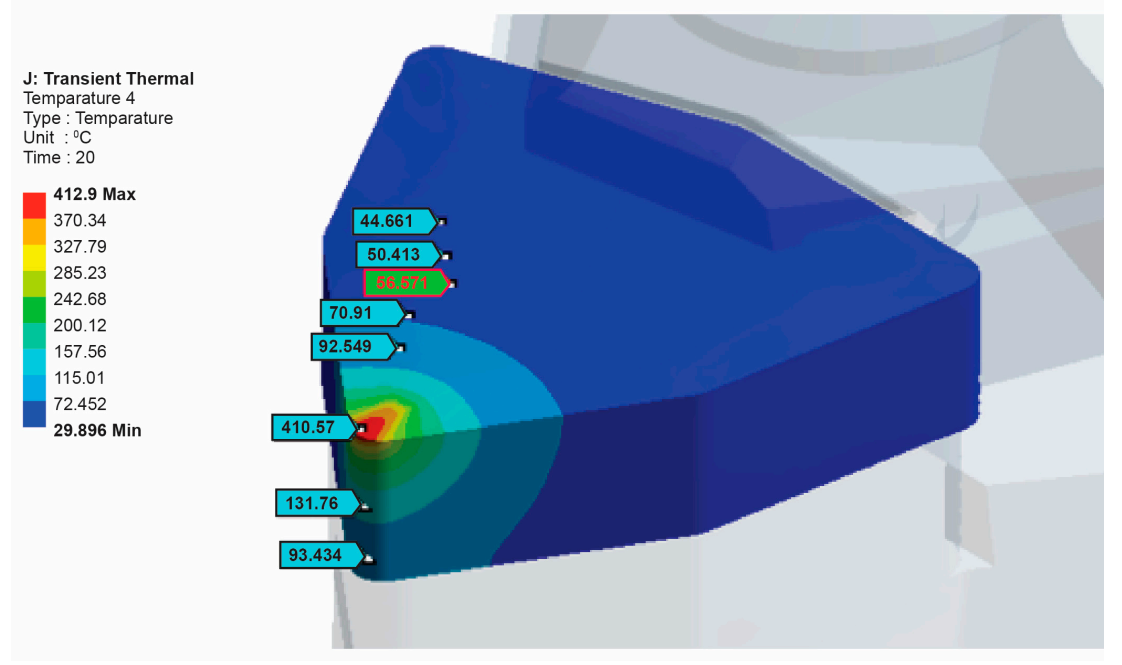

Figure 17. Temperature probe values for some locations.

\section{Conclusions}

In the present paper, techniques using an IR pyrometer and a K-type thermocouple were used simultaneously to measure the tool-chip interface and the tool temperature in turning heat-treated AISI 4140 alloy steel (hardness 50 HRC). This multi-sensor application in metal cutting provided information about the effects of cutting parameters on heat distribution. These applications (both chip temperature and tool temperature measurements) are unique in a machining context, and not many related works on the subject have been encountered in the literature. The heat distribution of the cutting tool, tool-chip interface and workpiece can provide useful information about the optimization of selected cutting parameters. Therefore, it is essential that the relationship between the cutting parameters and heat distribution be determined.

It was concluded that the cutting speed was the parameter most affecting the tool-chip interface temperature. The effect of the feed rate was not significant. Both parameters had similar effects on the tool temperature. Significant changes in the form and curvature of the chip were also observed as the cutting speed increased.

A 3-D finite element simulation model was also developed for the replication of the temperature based on the estimated heat over the tool-chip contact area. Comparison of the temperature values obtained by the finite element and the experimental results showed good agreement which means the FEM model of heat distribution was accurately constructed for use in future studies. The FEM analysis was essential in order to verify the test results.

\section{Acknowledgments}

This work is based on the project supported by the Uludag University Scientific Research Projects Unit TBMYO 2013/20. The authors express their appreciation to ISCAR TOOL AB, BURSA for providing the cutting tools. 


\section{Author Contributions}

M. Cemal Cakir, as the supervisor of the group, defined the general statement of the research. Experiments were designed, performed and analyzed by Abdil Kus, Yahya Isik and Salih Coskun. The FEM simulation and literature comparisons were done by Kadir Özdemir. Abdil Kus provided figures and data for the paper. All authors have read and approved the final manuscript. Correspondence and requests for the paper should be addressed to Abdil Kus.

\section{Conflicts of Interest}

The authors declare no conflict of interest.

\section{References}

1. Abukhshim, N.A.; Mativenga, P.T.; Sheikh, M.A. Investigation of heat partition in high speed turning of high strength alloy steel. Int. J. Mach. Tools Manuf. 2005, 45, 1687-1695.

2. Abukhshim, N.A.; Mativenga, P.T.; Sheikh, M.A. Heat generation an temperature prediction in metal cutting: A review and implications for high speed machining. Int. J. Mach. Tools Manuf. 2006, 46, 782-800.

3. Lowen, E.G.; Shaw, M.C. On the analysis of cutting tool temperatures. Trans. ASME 1954, 76, 217-231.

4. Davies, M.A.; Ueda, T.; Saoubi, R.M.; Mullany, B.; Cooke, A.L. On the measurement of temperature in material removal processes. Ann. CIRP 2007, 56, 581-604.

5. Attia, M.H.; Cameron, A.; Kops, L. Distortion in Thermal Field around Inserted Thermocouples in Experimental Interfacial Studies, Part 4: End Effect. J. Manuf. Sci. Eng. 2002, 124, 135-145.

6. Woodbury, A. Effect of deterministic thermocouple errors on the solution of the inverse heat conduction problem. In Proceedings of the 5th International Conference on Inverse Problems in Engineering: Theory and Practice, Cambridge, UK, 11-15 July 2005.

7. Abhang, L.B.; Hameedullah, M. The Measurement of tool-chip interface temperature in the turning of steel. Int. J. Comput. Commun. Inf. Syst. (IJCCIS) 2010, 2, 1-5.

8. Stephenson, D.A. Tool-work thermocouple temperature measurement. ASME J. Eng. Ind. 1993, $115,432-437$.

9. Grzesik, W. Experimental investigation of the cutting temperature when turning with coated Index able inserts. Int. J. Mach. Tools Manuf. 1999, 39, 355-369.

10. Sullivan, O.; Cotterm, M. Temperature measurement in single point turning. J. Mater. Process. Technol. 2001, 118, 301-318.

11. Ay, H.; Yang, W.J. Heat transfer and life of metal cutting tools in turning. Int. J. Heat Mass Trans. 1998, 41, 613-623.

12. Yujing, S.; Jie, S.; Jianfeng, L.; Qingchun, X. An experimental investigation of the influence of cutting parameters on cutting temperature in milling Ti6AI4V by applying semi-artificial thermocouple. Int. J. Adv. Manuf. Technol. 2014, 70, 765-773.

13. Krishna, S.A.A.R.; Reddy, P.R. Temperature prediction in orthogonal machining of AI/SiCp Composites. Int. J. Emerg. Technol. Adv. Eng. 2012, 2, 223-229. 
14. Fata, A. Temperature measurement during machining depending on cutting conditions. $P \& A$ Sci. Technol. 2011, 1, 16-21.

15. Ranc, N.; Pina, V.; Herve, P. Optical measurements of phase transition and temperature in adiabatic shear bands in titanium alloys. J. Phys. 2000, 10, 347-352.

16. Lin, J., Lee, S.L.; Weng, C.I. Estimation of cutting temperature in high speed machining. Int. J. Mater. Technol. 1992, 114, 289-296.

17. Dewes, R.C.; Ng, E.; Chua, K.S.; Newton, P.G. Temperature measurement when high speed machining hardened mould/die steel. J. Mater. Process. Technol. 1999, 92-93, 293-301.

18. Darwish, S.; Davies, R. Investigation of the heat flow through bonded and brazed metal cutting tools. Int. J. Mach. Tools Manuf. 1998, 29, 229-237.

19. Young, H.T. Cutting temperatures response to flank wear. Wear 1996, 201, 117-120.

20. Chu, T.; Wallbank, J. Determination of the temperature of a machined surface. ASME J. Manuf. Sci. Eng. 1998, 120, 259-263.

21. Liang, L.; Hao, X.; Zhiyongb, K. An improved three-dimensional inverse heat conduction procedure to determine the tool-chip interface temperature in dry turning. Int. J. Ther. Sci. 2013, 64, 152-161.

22. Zgorniak, P.; Grdulska, A. Investigation of temperature distribution during milling process of Az91hp Magnesium Alloys. Mech. Mech. Eng. 2012, 16, 33-40.

23. Modern Metal Cutting: A Practical Handbook Hardcover, 1st ed.; Sandvik Coromant: Trosa Tryckeri AB, Sweden, 1994.

24. Marinov, V. Manufacturing Processes for Metal Products; Kendall Hunt Publishing Company: Dubuque, IA, USA, 2008; p. 75.

25. Sata, T.; Takeuchi, Y. Improvement of working accuracy of NC lathe by compensation for the thermal expansion of the tool. Ann. CIRP 1981, 30, 445-449.

26. Chiou, R.Y.; Lu, L.; Chen, J.S.J.; North, M.T. Investigation of dry machining with embedded heat pipe cooling by finite element analysis and experiments. Int. J. Adv. Manuf. Technol. 2007, 31, 905-914.

27. Optris Infrared Thermometers. Available online: http://www.optris.com (accessed on 18 November 2013).

28. Akbar, F.; Mativenga, P.T.; Sheikh, M.A. An investigation of the tool-chip interface temperature and heat partition in high speed machining of AISI/SAE 4140 steel with TiN coated tool. In Proceedings of the 35th International MATADOR Conference, Taipei, Taiwan, 18-20 July 2007; pp. 215-218.

29. Sutter, G.; Faure, L.; Molinari, A.; Ranc, N.; Pina, V. An experimental technique for the measurement of temperature fields for the orthogonal cutting in high speed machining. Int. J. Mach. Tools Manuf. 2003, 43, 671-678.

30. Tay, A.A.O.; Stevenson, M.G; Davis, V.G. Using Finite Element Method to Determine Temperature Distributions in Orthogonal machining. Process. Int. Mech. Eng. 1974, 188, 627-638.

(C) 2015 by the authors; licensee MDPI, Basel, Switzerland. This article is an open access article distributed under the terms and conditions of the Creative Commons Attribution license (http://creativecommons.org/licenses/by/4.0/). 